\title{
Increased Risk of Recurrent Acute Respiratory Infections in Children with Congenital Heart Disease: A Prospective Cohort Study
}

\author{
Mulyadi Muhammad Djer*, Emilda Osmardin, Badriul Hegar, Darmawan Budi Setyanto \\ Department of Child Health, Faculty of Medicine, Universitas Indonesia/Cipto Mangunkusumo National General Hospital, Jl. Salemba Raya No.6, \\ Jakarta, Indonesia \\ *Corresponding author. E-mail: muldjer@yahoo.com
}

Received date: May 8, 2020; Revised date: Sep 8, 2020; Accepted date: Sep 11, 2020

\section{Abstract}

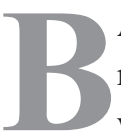

ACKGROUND: There is a lack of local data about recurrent acute respiratory infections in children with congenital heart disease (CHD). This study aims to investigate the incidence and recurrence of acute respiratory infection (ARI) in left-to-right shunt CHD.

METHODS: This prospective cohort study investigated children with left-to-right shunt CHD, aged three months to five years, at Dr. Cipto Mangunkusumo Hospital between September 2012 and April 2013. Age and sex-matched participants without CHD were recruited as reference. The occurrence of ARI was observed for six months. Acyanotic CHD patients from 2015 to 2019 were also evaluated to determine the proportion of ARI among this population.

RESULTS: A total of 100 subjects were enrolled in the study, 50 in the CHD group and 50 in the non-CHD group, six of whom were later excluded. The monthly incidence of ARI in the CHD group ranged between $40-60 \%(p=0.027)$. Subjects with CHD had a cumulative increased risk of $10 \%$ for acquiring ARI $(\mathrm{RR}=1.1 ; 95 \% \mathrm{CI}=1.02-1.2, p=0.027$ ). The proportion of subjects with a high recurrence of ARI was also higher in the CHD compared to the non-CHD group $(67 \%$ vs. $30 \%, p<0.001)$. The mean frequency of and median duration of ARI episodes was also higher in CHD compared to the non-CHD group, 3 vs. 1.5 episodes $(p<0.001)$, and 7 vs. 5 days, respectively.

CONCLUSION: Children with CHD are at an increased risk of ARI, with more episodes and longer duration compared to children without CHD.

KEYWORDS: non-cyanotic CHD, left-to-right shunt, acute respiratory infections

Indones Biomed J. 2020; 12(4): 355-60

\section{Introduction}

Congenital heart disease (CHD) is the most common type of congenital disorder, representing $28 \%$ of all forms of congenital disorders worldwide.(1,2) The incidence of CHD ranges from 6 to 10 cases in 1,000 live births, with significant symptoms being present in 50 percent of all patients.(3-6) Among the various types of CHD, the noncyanotic type is more often seen in practice $(76.7 \%)$, with the most common being ventricular septal defect (VSD), occurring in 2 of 1000 live births, followed by atrial septal defect (ASD), persistent ductus arteriosus (PDA), and atrioventricular septal defect (AVSD).(7) Congenital heart disease can lead to significant morbidity and mortality, as well as a high health expenditure burden.

One of the significant and problematic morbidities in children with CHD is infection, which frequently interacts with malnutrition, resulting in a complex health problem. Patients with an acute infection, such as acute respiratory infection (ARI), will experience anorexia, malabsorption, or metabolic disorders. Inadequate calorie intake may lead to weight decline, stunting, impaired immunity, and mucosal damage. Changes in lung circulation may lead to structural abnormalities accompanied by impairment in local cellular immunity, rendering children to be more vulnerable to 
ARI.(8) Children with CHD also have ventricular function impairment, which subsequently increases pulmonary pressure, resulting in capillary leak and lung edema.(9)

Recurrences of ARI are often seen in CHD patients, especially in infants less than one year old. $(4,10)$ Data from a study investigating 2,952 children with recurrent pneumonia showed that 22 children $(9 \%)$ have CHD, of which 16 were left-to-right shunt types.(11) Other studies reported that morbidities and mortality following ARI in acyanotic left-to-right shunt are higher than that in healthy children.(12,13) Previous studies evaluating the recurrence of ARI in children with CHD have used cross-sectional or retrospective data, but this is the first study in Indonesia using prospective data to estimate the recurrence of ARI among children with CHD. This study aims to compare the number of episodes, recurrence, and duration of ARI between children with acyanotic left-to-right shunt CHD and those without CHD.

\section{Methods}

\section{Study Design and Setting}

This prospective cohort study was conducted in the Department of Child Health and Integrated Heart Service of Dr. Cipto Mangunkusumo Hospital, Jakarta, Indonesia, between September 2012 and April 2013. With the twosample proportion test (proportion $40 \%$, power $80 \%$, level of significance 0.05 ), the minimum sample size requirement for each group was 40. Additional data of patients with acyanotic congenital heart disease in the hospital from 2015 until 2019 were also investigated to identify the proportion of acute respiratory infection among this population.

\section{Inclusion and Exclusion Criteria}

Patients diagnosed with acyanotic left-to-right shunt CHD aged between 3 months and 5 years old were consecutively enrolled in the study. Children without CHD, matched for age and sex, who visited the general pediatric outpatient clinic were recruited as the control group. Patients with other congenital diseases, chronic diseases, severe malnutrition, atopy, immunodeficiency (cancer, human immunodeficiency virus infection, receiving immunosuppressive agents) were excluded from the study. Patients who could not be contacted or evaluated, underwent cardiac surgery, or died, were dropped out and excluded from analysis. The episodes were documented using a parenting diary, which was collected every month during the routine ambulatory visits. Follow-up were also conducted by telephone.
To control for confounding factors in our analysis, we matched the CHD and reference group for age and sex and excluded children with severe malnutrition. The reference group also underwent an echocardiography examination to rule out the presence of any CHD. The reasons for age range selection in our study included the fact that ARI is more prevalent in children less than five years of age, and pulmonary resistance begins to decline at the age of two to three months when symptoms due to left-to-right shunt becomes more prominent.

Parental informed consent was obtained for every subject, and ethical approval for this study was obtained from the Research Ethics Committee of the Faculty of Medicine, University of Indonesia, Cipto Mangunkusumo Hospital, file number: 634/PT02.FK/TIK/2012, on October $12^{\text {th }}, 2012$.

\section{Operational Definitions and Clinical Outcome}

The diagnosis of acyanotic left-to-right shunt CHD was established based on echocardiography evaluation by one of the investigators, a pediatric cardiology consultant. A significant acyanotic left-to-right shunt was defined as a situation in which the patient required medication to control heart failure, suffered from moderate-to-severe pulmonary hypertension, or was cyanotic.

Upper ARI was defined as an infection of the upper respiratory tract (from nose to larynx) lasting for less than 14 days, during which the patient had a fever and showed any of the following symptoms: cough, runny nose, sore throat, hoarseness, nasal obliteration, or runny ear. Bronchial or pulmonary infection that occurred for less than 14 days and resulted in fever and dyspnea was classified as lower ARI. A high recurrence of ARI was defined as having three or more episodes of ARI or at least one episode of lower ARI within six months. Recovery of ARI was determined as the resolution of fever or respiratory symptoms or upon hospital discharge, whichever one occurs earlier. The incidence of ARI was defined in number of times.

\section{Data Analysis}

The baseline characteristics of the study participants was presented as percentage or median, as appropriate. To evaluate the effect of left-to-right shunt CHD on the monthly and cumulative incidence of ARI, unadjusted relative risk was used, while the Chi-squared test was applied to evaluate the effect of CHD on ARI recurrence level. The data obtained was then analyzed using Statistical Package for the Social Sciences (SPSS) version 19.0 (IBM Corporation, Armonk, New York, USA). 


\section{Results}

During the study period, 50 subjects were enrolled in each group. During the follow-up, 2 subjects died, 1 underwent defect closure, and 3 were loss-to-follow-up, resulting in 94 subjects to be analyzed ( 45 subjects in the CHD group and 49 subjects in the control group). From the additional data obtained, there were 334 subjects with acyanotic left heart disease in 2015-2019, of whom 156 had a history of pneumonia.

In the CHD group, there were more girls than boys (1.3:1), but the median age was similar between the two groups (Table 1). There were more moderately malnourished children in the CHD group compared to the non-CHD group (68\% vs. 26\%). Likewise, low socioeconomic status was also more common in the CHD group ( $80 \%)$ than the reference group $(36 \%)$. In terms of the type of $\mathrm{CHD}$, the most common lesion was VSD (50\%), followed by ASD, PDA, ASD with PDA, and VSD with PDA $(16 \%, 14 \%, 6 \%$, and $8 \%$ ), respectively. Significant left-to-right shunt CHD was found in 37 subjects $(74 \%)$.

The incidence of ARI in each month and the RR of ARI in the CHD compared to the non-CHD group are presented in Table 2. The incidence of ARI in the CHD group during the six-month follow-up period ranged from $40 \%$ to $60 \%$, whereas in the reference group it was $20 \%$ to $40 \%$, with a RR of 1.9 to 2.3 times.

There was a statistically significant difference in the 6-month cumulative incidence of ARI between the two groups, in which children with CHD had a cumulative incidence of almost twice (118 compared to 66 cases) that of children without CHD. The likelihood of CHD children having lower ARI was also higher, which was 8.6 times that of the non-CHD group. Mean ARI episodes within 6 months in the CHD group was also double of that of the reference group, which was 3 (SD 1.1) vs. 1.5 (SD 0.9) times.

In terms of recurrences, children with CHD were more likely to have high recurrence than those without $\mathrm{CHD}$, as seen in Table 3. The median ARI duration was also longer in the CHD group compared to the reference group, at 7 (4-14) days versus $5(2-12)$ days.

\section{Discussion}

In this study, we found that children with CHD had around twice the risk of having ARI each month with an almost 9-fold risk of lower ARI compared to those without CHD. The risk of infection recurrence and longer duration of illness was also more likely in children with CHD.

Table 1. Characteristics of study participants.

\begin{tabular}{|c|c|c|}
\hline Variable & $\begin{array}{l}\text { CHD Group } \\
(n=50)\end{array}$ & $\begin{array}{c}\text { Control group } \\
\qquad(\mathbf{n}=\mathbf{5 0})\end{array}$ \\
\hline \multicolumn{3}{|l|}{ Sex, n (\%) } \\
\hline Male & $22(44 \%)$ & $22(44 \%)$ \\
\hline Female & $28(56 \%)$ & $28(56 \%)$ \\
\hline Age (months), median (min-max) & $16(3-60)$ & $16(3-60)$ \\
\hline \multicolumn{3}{|l|}{ Nutritional status, $\mathrm{n}(\%)$} \\
\hline Moderately malnourished & $34(68 \%)$ & $12(24 \%)$ \\
\hline Well-nourished & $16(32 \%)$ & $38(76 \%)$ \\
\hline \multicolumn{3}{|l|}{ Maternal education, $\mathrm{n}(\%)$} \\
\hline Low & $14(28 \%)$ & $4(8 \%)$ \\
\hline Middle & $28(56 \%)$ & $13(26 \%)$ \\
\hline High & $8(16 \%)$ & $33(66 \%)$ \\
\hline \multicolumn{3}{|l|}{ Paternal education, n (\%) } \\
\hline Low & $9(18 \%)$ & $2(4 \%)$ \\
\hline Middle & $30(60 \%)$ & $16(32 \%)$ \\
\hline High & $11(22 \%)$ & $32(64 \%)$ \\
\hline \multicolumn{3}{|l|}{ Socioeconomic status, $\mathrm{n}(\%)$} \\
\hline Low & $40(80 \%)$ & $18(36 \%)$ \\
\hline Middle to low & $8(16 \%)$ & $20(40 \%)$ \\
\hline Middle to high & $2(4 \%)$ & $12(24 \%)$ \\
\hline
\end{tabular}


Table 2. Incidence of ARI in CHD and control group for six months.

\begin{tabular}{|c|c|c|c|c|c|c|c|c|}
\hline \multirow{2}{*}{ Month } & \multirow{2}{*}{ Group } & \multicolumn{2}{|c|}{ ARI } & \multirow{2}{*}{$\mathbf{n}$} & \multirow{2}{*}{$\begin{array}{c}\text { Incidence } \\
(\%)\end{array}$} & \multirow{2}{*}{$\mathbf{R R}$} & \multirow{2}{*}{$\begin{array}{c}95 \% \text { CI of } \\
\text { RR }\end{array}$} & \multirow{2}{*}{$p^{1}$} \\
\hline & & Yes & No & & & & & \\
\hline \multirow[t]{2}{*}{ I } & CHD & 23 & 27 & 50 & 46 & 2.3 & $1.2-4.3$ & 0.006 \\
\hline & Control & 10 & 40 & 50 & 20 & & & \\
\hline \multirow[t]{2}{*}{ II } & CHD & 20 & 29 & 49 & 40.8 & 2 & $1.1-3.9$ & 0.024 \\
\hline & Control & 10 & 40 & 50 & 20 & & & \\
\hline \multirow[t]{2}{*}{ III } & CHD & 19 & 26 & 45 & 42.2 & 1.9 & $1.1-3.6$ & 0.034 \\
\hline & Control & 11 & 39 & 50 & 22 & & & \\
\hline \multirow[t]{2}{*}{ IV } & CHD & 27 & 18 & 45 & 60 & 2 & $1.2-3.2$ & 0.003 \\
\hline & Control & 15 & 35 & 50 & 30 & & & \\
\hline \multirow[t]{2}{*}{$\mathrm{V}$} & CHD & 25 & 20 & 45 & 55.5 & 2.2 & $1.3-3.9$ & 0.004 \\
\hline & Control & 12 & 37 & 49 & 24.4 & & & \\
\hline \multirow[t]{2}{*}{ VI } & CHD & 23 & 22 & 45 & 51.1 & 2.2 & $1.2-4.1$ & 0.004 \\
\hline & Control & 11 & 38 & 49 & 22.4 & & & \\
\hline \multirow[t]{2}{*}{ Cumulative } & CHD & 45 & 0 & 45 & 100 & 1.1 & $1.03-1.2$ & $0.027^{*}$ \\
\hline & Control & 43 & 6 & 49 & 87.7 & & & \\
\hline
\end{tabular}

${ }^{1}$ tested with Chi-square; *Tested with Exact-Fisher.

In general, malnutrition is related to the inadequate intake and absorption of nutrients, high energy expenditure, and recurrent ARI. One study found that the prevalence of malnutrition in CHD (cyanotic and acyanotic) children was $51.1 \%$, of whom $22.3 \%$ were severely malnourished, and body weight was found to be more affected than body length (72.2\% vs. 49.3\%).(14) Another study concluded that there was a significant difference in nutritional status between patients with and without CHD.(15) This study analysed all subjects as a whole and did not compare acyanotic to cyanotic CHD or non-CHD children. Parental education level was inversely correlated with the incidence and mortality of ARI.(16) One study found that parental education level was related to the incidence of ARI.(17) Another study also found a significant correlation between maternal education and the incidence of ARI, but not paternal education.(18) In contrast, some studies found that parental education level was not related to the incidence of ARI. $(8,19)$

In this study, the socioeconomic status of most of the subjects in the CHD group was found to be low, whereas that in the control group ranged from low to moderate. As stated in a previous study, children from a lower socioeconomic status have a higher risk of acquiring infections, especially ARI, as it increases the likelihood of infection exposure and decreased immunity.(20) Exposure to infection may increase due to poor sanitation and hygiene as well as an overcrowded living environment. Body defence mechanisms may decrease due to nutritional deprivation, less access to vaccinations, and exposure to polluted air and cigarettes. A previous study found that children from low socioeconomic groups are 3.3 times more likely to have ARI than those from moderate-to-high socioeconomic groups.(21)

Ventricular septal defect (VSD) was the most common type of CHD found in this study, which was $33.1 \%$ of all CHD types, whereas ASD and PDA was found in $8 \%-13 \%$ and 6\%-11\% CHD patients.(22) In our study, we also found combinations of anatomical defects such as ASD, PDA, and VSD. The characteristics of CHD types in our study were similar to that of a previous study, evaluating the profile of CHD at a teaching hospital in India.(23) The authors found that VSD (42.6\%) was the most prevalent defect, followed by ASD (14.8\%) and PDA (7.8\%). Another study also revealed similar results, reporting that VSD was found in $24 \%$ of subjects, whereas PDA, ASD, ASD and VSD, ASD and PDA, and VSD and PDA were found in 6.6\%, 6.5\%, $0.6 \%, 0.3 \%$, and $0.1 \%$ of subjects respectively.(24) Most of CHD patients with recurrent pneumonia has left-to-right shunt type.(11)

Table 3. Recurrence of ARI in CHD and control group.

\begin{tabular}{|c|c|c|c|}
\hline \multirow{2}{*}{$\begin{array}{c}\text { Risk Factor } \\
\text { Group }\end{array}$} & \multicolumn{3}{|c|}{ Recurrences of ARI } \\
\hline & $\begin{array}{c}<3 x / 6 \text { month } \\
(\text { n }(\%))\end{array}$ & $\begin{array}{c}\geq 3 x / 6 \text { month } \\
(n(\%))\end{array}$ & $p^{*}$ \\
\hline CHD & $15(33)$ & $30(67)$ & $<0.0001$ \\
\hline Control & $43(87)$ & $6(13)$ & \\
\hline Total & $58(61)$ & $36(39)$ & \\
\hline
\end{tabular}

*Tested with Mann-Whitney. 
This study found that the incidence of ARI in each group was quite stable over the months. However, in the fourth month of follow-up, there was a little upsurge in the occurrence of ARI due to a flood catastrophe in Indonesia. When we compared the monthly incidence of ARI between groups, it was higher in the CHD group compared to the non-CHD group. It has been suggested that the incidence of ARI in urban areas is slightly higher (20\%) compared to rural areas (17.7\%).(9) Similar findings regarding the incidence of ARI in urban and rural areas was also found in this study.

Upper ARI comprises of rhinitis, pharyngitis, tonsillitis, sinusitis, and otitis media, whereas lower ARI includes bronchitis, bronchiolitis, and pneumonia.(16) This study found that lower ARI were more prevalent in the CHD group. Among 29 patients with lower ARI from both groups, 27 were admitted to the hospital, but 2 subjects refused to be hospitalized. One study in 2004-2006 was conducted on children of less than 24 months with significant cardiac abnormalities to evaluate hospital admission for ARI.(25) Of the 1,248 patients, $167(13.4 \%)$ out of 210 were hospitalized with the following diagnosis: bronchiolitis (41.7\%), upper ARI (28.1\%), pneumonia (17.6\%), and other infections (18.6\%). The risk factors identified included the presence of a certain syndrome, incomplete RSV prophylaxis, prematurity, and malnutrition. The proportion of lower ARI in Dr. Cipto Mangunkusumo Hospital (2015 to 2019) was found to be almost $50 \%$. This finding was higher compared to previous studies.(26)

The mean episode of ARI among the CHD patients in this study during six months of observation was 3 (SD 1.1) times, whereas, in the control group, it was 1.5 (SD 0.9) times. During the observation, six subjects in the control group had no episode of ARI. A previous study also observed higher mean episode of ARI among patients with CHD, at almost four times higher in children with acyanotic CHD.(8) This difference may result from different lengths of follow-up, CHD classification, and definition of ARI. Another study showed that children with acyanotic CHD experienced 4.94 (SD 2.54) episodes of ARI annually, which was significantly higher compared to cyanotic CHD at 2.41 (SD 1.89), $(p=0.01) .(27)$ The incidence of ARI episodes in acyanotic left-to-right shunt is significantly higher (5.08 (SD 2.55)) than conotruncal anomaly, which was similar with our findings. Some authors define recurrent ARI as respiratory infections occurring at least six times per year or at least three times per year if it involves the lower respiratory tract.(28) In this study, we defined recurrent ARI as the occurrence of ARI for three times or more within a period of 6 months. Based on this definition, we found a higher percentage $(67 \%)$ of subjects with CHD who had recurrent ARI compared to that in those without CHD (13\%). Our findings were similar to findings from a previous study, although they found a less contrasting difference between the CHD and non-CHD groups (51.7\% vs. $30.7 \%$, respectively) due to different definitions of recurrent ARI, which was more than six episodes per year. (15) The differences in the above data can also be attributed to the different study design applied between two studies, and the definition of ARI used in the questionnaires.

We found that the duration of ARI in the CHD group was longer than that in the reference group. In a previous study, the median duration of ARI in children with CHD was slightly shorter than that in our findings, which was 3.5 (2.9 to 4.5) days in non-cyanotic CHD and 4.1 (3.2 to 4.9) days in cyanotic CHD.(8)

In this study, CHDs were classified based on cyanotic symptoms, and non-cyanotic CHD was not further divided based on pressure and volume loads. In a previous study, ARI was grouped by the length of duration, which was seven days or less (short episode) and more than seven days.(15) That study found that percentage of children with a short episode of ARI was almost similar between the CHD and non-CHD groups. However, more children with CHD (19\%) had ARI of more than seven days compared to the reference group $(1.7 \%)$. Compared to this study, the previous study used a different design and eligibility criteria, such as age range, severe malnutrition, immunocompromised status, and presence of atopy.

There are several limitations in this study. Firstly, the measurement of ARI episodes were based on parental reports, which could be influenced by the subjectivity of parents (recall bias). Secondly, no laboratory examinations were conducted to explore the etiology of ARI. Thirdly, other factors that can influence the risk of acquiring ARI, such as hygiene, pollution, access to health care, and treatment were not evaluated and documented. Lastly, different characteristics between the CHD and non-CHD groups were observed in terms of nutritional status, education, and socioeconomic level, which can affect the incidence of ARI.

\section{Conclusion}

This prospective cohort study found that children with a non-cyanotic left-to-right shunt CHD have almost twice the risk for having ARI with a higher risk of recurrence and longer duration compared to children without CHD. 


\section{References}

1. Liu Y, Chen S, Zuhlke L, Black GC, Choy MK, Li N, et al. Global birth prevalence of congenital heart defect 1970-2017: updated systematic review and meta-analysis of 260 studies. Int J Epidemiol. 2019; 48: 455-63.

2. Linde D, Konings EEM, Slanger MA, Witsenburg M, Helbing WA, Takkenberg JJM, et al. Birth prevalence of congenital heart disease worldwide. J Am Coll Cardiol. 2011; 58: 2241-7.

3. Djer MM. Penanganan Penyakit Jantung Bawaan Tanpa Operasi (Kardiologi Intervensi). Jakarta: CV Sagung Seto; 2014.

4. Checchia PA, Paes B, Bont L, Manzoni P, Simoes EAF, Fauroux $\mathrm{B}$, et al. Defining the risk and associated morbidity and mortality of severe respiratory syncytial virus infection among infants with congenital heart disease. Infect Dis Ther. 2017; 6: 37-56.

5. Saxena A. Congenital heart disease in India: a status report. Indian Pediatr. 2018; 55: 1075-82.

6. Murni IK, Djer MM, Yanuarso PB, Putra ST, Advani N, Rachmad J. et al. Outcome of pediatric cardiac surgery and predictors of major complication in a developing country. Ann Pediatr Cardiol. 2019; 12: $38-44$.

7. Columbia University [Internet]. Williams IA. Cardiovascular pathophysiology: left to the right shunt [updated 2008; cited 2012 Agu 14]. Available from: http://www.columbia.edu/itc/hs/medical/ pathophys/cardiology/2008/leftrightshuntsColor.pdf.

8. Wilar R, Wantania JM. Beberapa faktor yang berhubungan dengan episode infeksi saluran pernapasan akut pada anak dengan penyakit jantung bawaan. Sari Pediatri. 2006; 8: 154-8.

9. Gekey JM, Cyran SE. Managing the morbidity associated with respiratory viral infections in children with congenital heart disease. Int J Pediatr. 2012; 20: 646780. doi: 10.1155/2012/646780.

10. Djer MM. Panduan Klinis Praktis Pemeriksaan Kardiovaskular Pada Anak: Strategi Memahami Bunyi dan Bising Jantung Dengan Mudah. Jakarta: CV Sagung Seto. 2019.

11. Montella S, Corcione A, Santamaria F. Reccurent pneumonia in children a reasoned diagnostic approach and a single centre experience. Int J Mol Sci. 2017; 18: 296-309.

12. Rodriguez DA, Rodriguez-Martinez CE, Cardenas AC, Quilaguy IE, Maorga LY, Falla LM, et al. Predictors of severity and mortality in children hospitalizedwith respitratory syncytial virus infection in a tropical region. Pediatr Pulmonol. 2014; 49: 269-76.

13. Lopez CM, Gracia-Guereta L. Acute respiratory infection and congenital heart disease. AAP Grand Rounds. 2011; 25: 33.

14. Sjarif DR, Anggriawan SL, Putra ST, Djer MM. Anthropometric profile of children with congenital heart disease. Med J Indones. 2011; 20: 40-5.
15. Monteiro FP, de Araojo TL, Lopes MV, Chaves DB, Beltrao BA, Costa AG, et al. Nutritional status of children with congenital heart disease. Rev Lat Am Enfermagem. 2012; 20: 1024-32.

16. Wantania JM, Naning R, Wahani A. Epidemiologi infeksi respiratori akut. In: Rahajoe NN, Supriyatno B, Setyanto DB, editors. Buku Ajar Respirologi Anak. 1st edition. Jakarta: Badan Penerbit IDAI; 2008. p.268-76.

17. Yousif TK, Khaleq BA. Epidemiology of acute respiratory infections (ARI) among children under five years old attending Tikrit general teaching hospital. Middle East J Fam Med. 2006; 4: 4-23.

18. Pore PD, Ghattargi CH, Rayate MV. Study of risk factors acute respiratory infection (ARI) in under five in Solapur. Nat J Com Med. 2010; 1: 64-7.

19. Nasution K, Sjahrullah MAR, Brohet KE, Wibisana KA, Yassien MR, Ishak LM, et al. Infeksi saluran napas akut pada balita di daerah urban Jakarta. Sari Pediatri. 2009; 11: 223-8.

20. Lafond KE, Nair H, Rasooly MH, Valente F, Booy R, Rahman M, et al. Global role and burden of inffuenza in pediatric respiratory hospitalizations, 1982-2012: a systematic analysis. PloS Med. 2016; 13: e1001977. doi: 10.1371/journal.pmed.1001977.

21. Breiman RF, Cosmas L, Njenga M, Williamson J, Mott JA, Katz MA, et al. Severe acute respiratory infection in children in a densely populated urban slum in Kenya, 2007-2011. BMC Infect Dis. 2015; 15: 95. doi: 10.1186/s12879-015-0827-x.

22. Rao PS. Diagnosis and management of acyanotic heart disease: Part II-left to the right shunt lesion. Indian J Pediatr. 2005; 72: 503-12.

23. Sharmin LS, Haque MA, Bari MI, Ali MA. Pattern of clinical profile of congenital heart disease in teaching hospital. TAJ. 2008; 21 : 5862.

24. Akhtar K, Maadullah, Ahmed W. Profile of congenital heart disease and correlation to risk adjustment for surgery; An echocardiographic study. J Coll Physicians Surg Pak. 2008; 18: 334-7.

25. Chang RKR, Chen AY. Impact of palivizumab on RSV hospitalizations for children with hemodynamically significant congenital heart disease. Pediatr Cardiol. 2010; 31: 90-5.

26. Lopez CM, Silva GG. Respiratoty infections and congenital heart disease: two season of civic. An Pediatr (Barc). 2007; 67: 32936.

27. Caffarelli C, Santamaria F, Di Mauro D, Mastrorilli C, Montella S, Bernasconi S, et al. Advances in pediatrics in 2016: current practices and challenges in allergy, autoimmune disease, cardiology, endocrinology, gastroenterology, infectious diaseases, neonatolgy, nephrology, neurology, nutrition, pulmonology. Ital J Pediatr. 2017; 43: 80-96.

28. Jesenak M, Ciljakova M, Rennerova Z, Babusikova E, Banovcin P. Recurrent respiratory infections in children-definition, diagnostic approach, treatment and prevention. Martin-Loeches I, editor. In: Bronchitis. London: IntechOpen, 2011. doi: 10.5772/19422. 